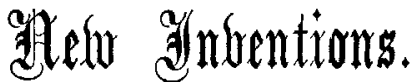

\section{AN IMPROVED ADJUSTABLE COMMODE.}

THIS commode admits of a variety of adjustments, in one of which it presents an entirely horizontal surface, as shown in Fig. 2 It will, therefore, sometimes be serviceable in cases where the bed-pan cannot be used. Its height can be adjusted to that of the bedstead. The seat is of a good size and shape, like an ordinary water-closet seat, instead of a small round hole as usually found in commodes, and it is so constructed that it can be slightly raised at the foot end and

FIG. 1.

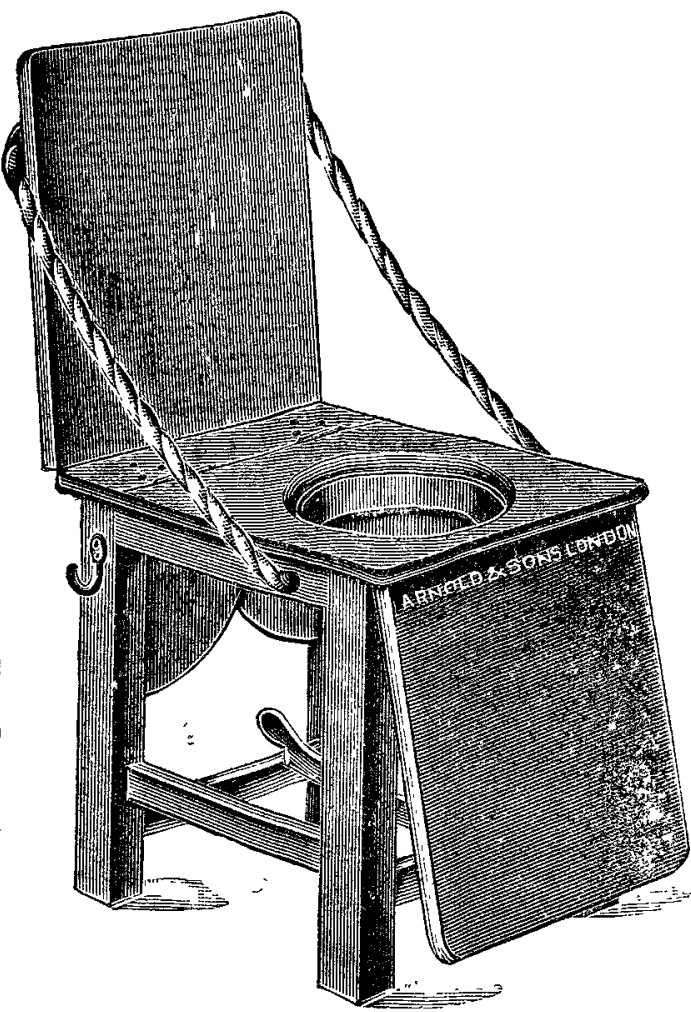

table. Massrs. Arnold and $\mathrm{S} v n$ s of $\mathrm{We}$ : Smithfield, London, E.C., are the makers of the commode.

$$
\text { J. LIONEL STRETTON, }
$$

Senior Surgeon, Kidderminster Infirmary and Children's Hospital.

Kidderminster. so prevent a patient from slipping down. The lid which forms the section for the support of the upper portion of the body can be placed horizontally or it can be raised to various heights so that a patient may sit upright or partially so. When raised it is retained in position by strrng pieces of cable which form side supports so that it resembles an arm chair, as shown in Fig. 1. If a patient is too helpless to be supported in this way the lid can be folded back and an attendant can stand behind to give the necessary assistance. The section which forms the support for the lower extremities may either be maintained in the horizontal position, as shown in the illustration, or it may be folded down in order to allow the feet to be placed on a hassock. If desired it can be provided with a sliding foot-piece for this purpose. In cases where it is desirable to keep one leg only horizontal the section can be divided longitudinally so that one foot only is lowered. When not in use, the lower section hang; down in front and the upper section is folded over the seat, forming a useful bedside

FIG. 2.

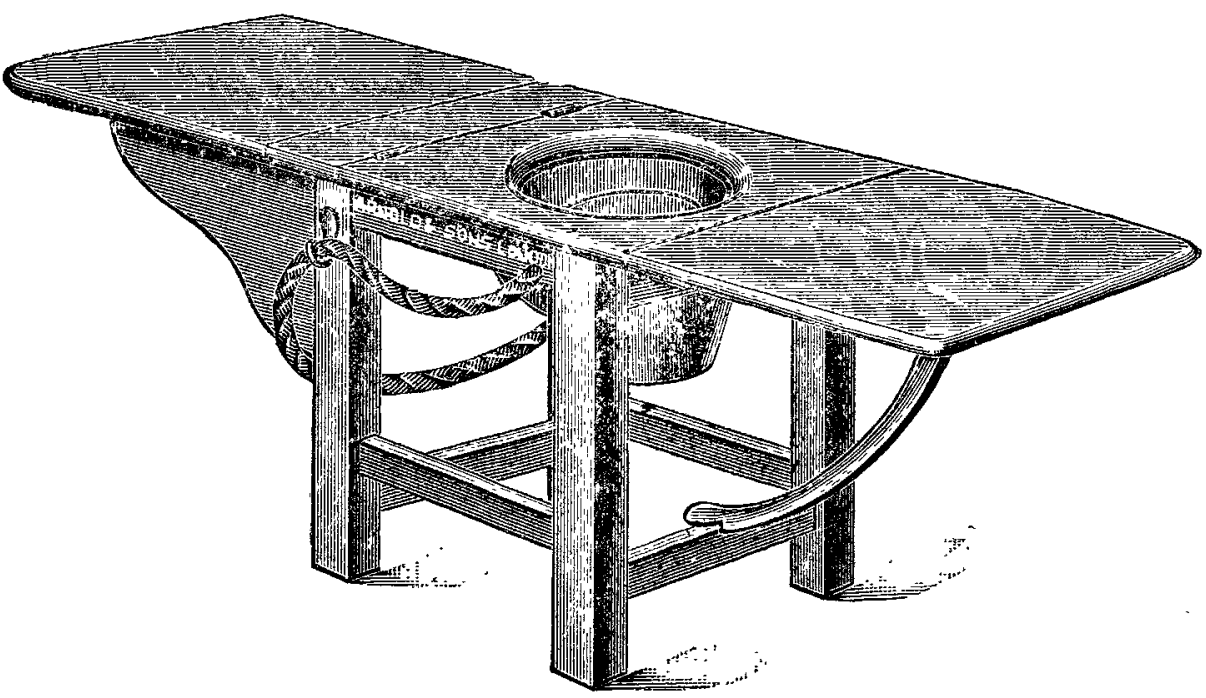

\section{A REST FOR FLEXION OF THE THIGHS AFTER ABDOMINAL OPERATIONS}

HAVING noticed how invariably patients require their thighs flezed after abdominal operations and the frequency with which the usual pillows require readjusting, I venture to think that the rest shown in the illustration will be found useful. One of the chief points of the rest is that it provides a firm resisting plane for the thigh at an angle, the heels being allowed to touch the bed (Fig. 1). The rest is made in two sizes to suit long and

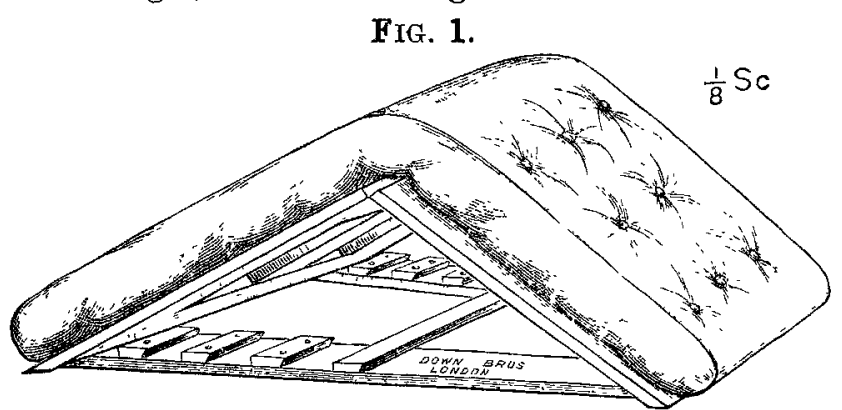
short thighs. I have used these appliances for some time and they have given great comfort.

The wedge-shaped bolster (Fig. 2) is, I think, the ideal for hospital use where so many patients have to lie on their backs for a considerable period.

The bolster enables the shoulders to be slightly elevated, thus leaving the neck straight. As the patient progresses and is able to have a pillow as well it is even more comfortable, being FIG. 2.

less abrupt than the round bolster or two pillows.

Both the leg rest and the bolster have been most carefully prepared by Messrs. Down Bros. Limited, of St. Thomas's street, Borough, S.E., from whom they can be procured.

\section{A. Z. C. CRESSY,} M.R.C.S. Eng., \&c.

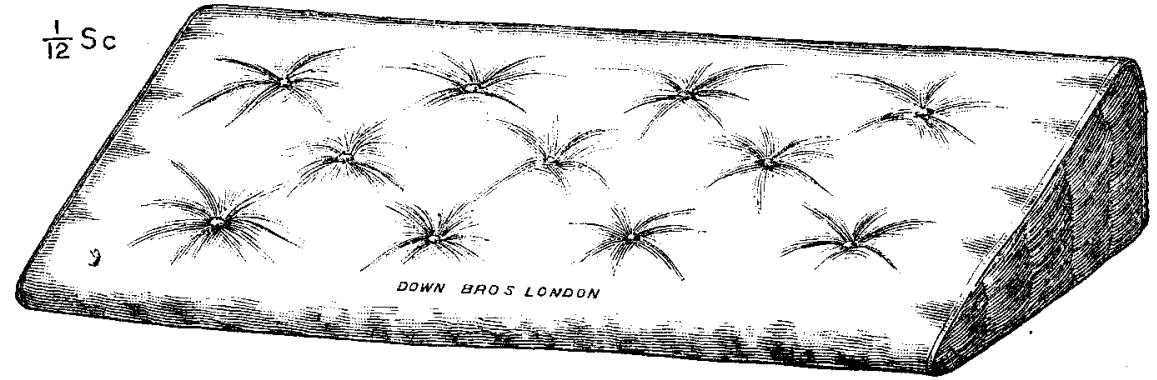

